\title{
MOTIVATION OF MANUAL WORKERS THROUGH SAFE USE OF PESTICIDES
}

\author{
H.S.R. Rosiro
}

\begin{abstract}
This exploratory study was undertaken in an attempt to analyse how safe working habits of the handling of pesticides by manual workers in foliage farms in Sri Lanka affect work motivation and to propose strategies to improve work motivation. The study was conducted on five foliage plant exporting companies located within the Negombo area in Sri Lanka and the sample consisted of ten executives and hundred manual workers. Data were collected using questionnaires administered through structured interviews and by observations. Work motivation has been measured indirectly through workers' attitude, degree of happiness and satisfaction. Independent variables of the study were existing working conditions, safety precautions taken in the use of pesticides and workers' attitude towards handling pesticides. Six other factors contributory towards work motivation were also studied. The study proved that work motivation has a relationship with three independent variables. Strategies of reinforcement of safe working habits and strategies on other aspects of working were recommended to improve work motivation.
\end{abstract}

\section{INTRODUCTION}

Foliage plant exports are an important sector of Sri Lankan economy. The contribution from foliage plant export sector to the economy is around Rs. $250-$ 300 million per annum (Sri Lanka Customs, 2002).

Extensive usage of pesticides is a common feature of the commercial foliage sector in Sri Lanka. These pesticides can be categorized as fungicides, herbicides, nematicides, bactericides etc. All these types are hazardous to human beings. But the fact remains that the workers are forced to use these pesticides on the instructions of the managements of the farms. As a result, workers have developed a negative mindset and thus difficult to motivate.

Nationally and internationally, agriculture is more and more dependant on pesticides. This may be due to increasing labour cost, demand for higher yields and increasing competition in the market to globalisation. Globally the popularity of chemical pesticides is on the decline and Integrated Pest Management is the current concern. However, the world pesticide market grew rapidly during the last decade with sales that are estimated to be over US\$ 25 billion annually. In the 1990's also, the market growth has been very positive in Asia and Africa. This expansion is, in part related to increased promotion of the use of herbicides but also to the availability of cheap, but risky, older chemicals that are marketed by some manufacturers in certain countries. These pesticides are leading to increased farm worker risk. (Schillhorn van Veen, 2002). Proper control of use of pesticides is an area of concern in Sri Lanka. All pesticides are toxic to life. There is an increasing awareness that pesticides can result in serious, complex and subtle health risks. Attempts have been reported by workers of farms trying to import banned pesticides. Therefore, it can be stated that use of pesticides poses a definite issue of health and occupational hazards and an issue of work motivation.

\section{Objectives}

The general objective of this article is to discuss how safety needs associated with handling of pesticides are satisfied by manual workers of commercial foliage farms and whether it results in work motivation. The foliage plant export industry in Sri Lanka has been selected for the study.

The specific objectives of this study are to;

1. Study the attitudes and behaviour of farm manual workers towards usage of pesticides. 
2. Propose strategies to improve positive attitudes thereby increasing the work motivation under such conditions.

In relation to the above objectives of this study following null hypothesis was framed.

$\mathrm{H}_{0}$ :- $\quad$ The negative attitudes, unhappiness and dissatisfaction are independent of the present working conditions, safety precautions taken in the use of pesticides and attitudes towards handling pesticides by self.

\section{METHODOLOGY}

\section{Variables of the study}

Three key independent variables; existing working conditions, safety precautions taken in the use of pesticides and attitude towards handling pesticides by self in the context of use of pesticides at working place were identified. To maintain simplicity of the study only six contributing factors (Table 01) have been identified for reasoning and proposal of strategies.

\section{Sampling procedure}

The population taken into consideration for this study was the manual workers and executives from five foliage plant export companies situated in and around Negombo, Sri Lanka. Executives have been selected to get an idea of working environments and general conditions in the respective companies. As the sample, two executives and twenty manual workers were selected from each company using simple random sampling method making a total sample of 10 executives and 100 manual workers. A mix of executives and manual workers were selected to obtain a balanced view of the working conditions and working methods of each company under study.

\section{Collection of data and analysis}

Primary data were collected through structured interviews using a questionnaire and by visual observations by researcher. The questionnaire was modified by a pilot survey and it was used to collect data from manual workers. It contained questions to be measured by a Likert scale and openended questions as well. Structured interviews were conducted to interview executives and visual data were utilized as back-up material specially in making proposals. Simple statistical measures such as percentages, mean values and chisquare value were utilized to analyse the data for inferences.

Table 01: Key variables and factors for analysis

\begin{tabular}{|c|c|}
\hline Key variables & Other factors for analysis and reasoning \\
\hline $\begin{array}{l}\text { 1. Overall existing working } \\
\text { conditions. } \\
\text { 2. Safety precautions taken in the } \\
\text { use of pesticides. }\end{array}$ & $\begin{array}{l}\text { 1. Need for safety from pesticides. } \\
\text { 2. Attitudes towards rewards for safe working } \\
\text { habits. } \\
\text { 3. Nature of encouragement needed by workers. }\end{array}$ \\
\hline $\begin{array}{l}\text { 3. Attitude towards handling } \\
\text { pesticides. }\end{array}$ & $\begin{array}{l}\text { 4. Workers' result orientedness and productivity } \\
\text { upon rewards for safe working habits. } \\
\text { 5. Organizational encouragement of workers' safe } \\
\text { working habits. } \\
\text { 6. Mode of contact with pesticides. }\end{array}$ \\
\hline
\end{tabular}




\section{RESULTS AND DISCUSSION}

\section{Testing of hypothesis}

Luthans (1995) explained that the negative attitudes at work or dissatisfaction have a direct effect on work motivation. This study and the analysis is based on how negative attitude and dissatisfaction is brought about by the three key variables under consideration and their linkage to work motivation. The Chi-Square statistic has been used to test the hypothesis. The percentages of workers satisfied or dissatisfied were measured against the three key variables which were the variables for the Chi-Square test for testing of hypothesis.

The Chi-Square value for the test was $49.96\left[\chi^{2}\right.$ table $\left.(0.001, \mathrm{df}=2)=13.82\right]$ (Table 02). Therefore, the null hypothesis that "the negative attitudes and dissatisfaction is independent of the present working conditions, safety precautions taken in the use of pesticides and attitudes towards handling pesticides by self" is rejected. This test therefore, establishes that the worker satisfaction, happiness and positive attitudes are dependant upon the present working conditions of the farm, safety precautions taken in the use of pesticides and the workers' attitudes towards handling pesticides by themselves. Since work motivation is linked with the satisfaction etc. (Luthans, 1995) it is inferred that the three variables have a direct influence on work motivation.
Therefore, following relationship is established by this study.

$$
\text { Work Motivation }=f\left(\mathrm{Y}_{1}, \mathrm{Y}_{2}, \mathrm{Y}_{3}\right)
$$$$
\text { Where; }
$$

$\mathrm{Y}_{1} \quad=$ Present working conditions

$\mathrm{Y}_{2}=$ Safety precautions taken in the use of pesticides

and $\mathrm{Y}_{3}=$ Attitudes towards handling pesticides by workers themselves

The following discussion of three key variables and the associated factors will provide an insight into the attitudes of workers towards using pesticides, organisational encouragement towards safe use of pesticides, the need for motivation and how could the workers be motivated.

\section{Basic characteristics of workers}

The average age of workers was 29 years with a standard deviation of 6.83 . Minimum and maximum ages were 21 and 48 respectively.Sixty eight percent of the workers were females and thirty two percent were males. Working in the foliage plant growing and exporting farms includes delicate and sophisticated activities of handling plants. These activities such as planting pruning and plant care require flexible hands and fingers. Also, executives pointed out that the farms prefer to employ females because they have the ability to treat plants tenderly and also women are less aggressive than men, hence easy to manage by supervisors.

Table 02: Chi-Square cross tabulation table.

\begin{tabular}{|c|c|c|c|}
\hline Variable & $\begin{array}{c}\text { Satisfied/ } \\
\text { positive/ } \\
\text { happy } \\
(\%)\end{array}$ & $\begin{array}{c}\text { Dissatisfied/ } \\
\text { negative/ } \\
\text { unhappy } \\
(\%)\end{array}$ & Total \\
\hline 1. Existing working conditions. & 7 & 93 & 100 \\
\hline $\begin{array}{l}\text { 2. Safety precautions taken in the use of } \\
\text { pesticides. }\end{array}$ & 36 & 64 & 100 \\
\hline 3. Attitude towards handling pesticides by self. & 3 & 97 & 100 \\
\hline Total & 46 & 254 & 300 \\
\hline
\end{tabular}


The data in Table 03 show that sixty eight percent of the workers have an education of up to eighth standard or above. This is an evidence to conclude that they are able to understand general commands and that they are rational in their thinking, acting and responding.

\section{Existing working conditions}

This study reveals that ninety three percent of the workers are aware that the jobs involving in handling pesticides are hazardous and have long lasting effects on human health. They are of the opinion that all the pesticides are "poisonous" and inorganic fertilizers are "hazardous".

Results in Table 04 show that sixty nine percent of the workers are not happy about the present working conditions offered by companies related to safety in using pesticides. The overall feeling is the expression of interaction among workers' attitudes towards safety, needs for safety, degree of safety maintained by each company, executives' safety consciousness,

Table 03: Educational background of workers.

\begin{tabular}{lc}
\hline \multicolumn{1}{c}{ Standard (up to) } & Percentage of respondents \\
\hline Fifth & 4 \\
Sixth & 16 \\
Seventh & 12 \\
Eighth & 43 \\
Ninth & 18 \\
GCE Ordinary Level & 6 \\
GCE Advanced Level & 1 \\
\hline
\end{tabular}

Table 04: Workers overall feeling about present farm working conditions.

\begin{tabular}{lll}
\hline \multicolumn{1}{c}{ Response } & Percentage respondents \\
\hline 1. Extremely un happy & 7 & \\
2. Unhappy & 62 & \\
3. No response & 26 & \\
4. Happy & 5 & \\
\hline
\end{tabular}

Table 05: Workers opinion about the safety conditions maintained by foliage farms.

\begin{tabular}{ll}
\hline \multicolumn{1}{c}{ Response about the present safety precautions } & Percentage respondents \\
\hline 1. Extremely unhappy & 3 \\
2. Unhappy & 61 \\
3. No response & 28 \\
4. Happy & 8 \\
\hline
\end{tabular}


company's commitment towards worker safety and company's encouragement towards safe working habits. The manual workers are working for a payment on which sometimes a family is depending. These workers, who therefore have no option, are compelled to work in the farms. They have to handle pesticides very often. This scenario is a considerable demotivating factor. It has been a difficult task to motivate these workers in this system of farm working life. Therefore, deliberate measures will have to be taken to improve these working conditions

Discussions revealed that the five percent of workers who feel happy about the present working conditions are of a very positive, optimistic and self-motivating type. This category should be made proper use of as role models when framing human resource strategies to motivate employees. Seven percent of the workers did not respond to the questions about working conditions and their awareness of hazards of pesticides. It should be noted that the above seven percent was apportioned among unhappy and happy categories to ease the statistical analysis.

The usage of pesticides in farms includes general handling, dispensing such as spraying, dipping etc., storage, transport, disposal of expired pesticides and cleaning of equipment and containers. Exposure or direct contact of pesticides will cause quick or in-situ injuries such as eye injuries, burns, inhalation of fumes causing damage to lung epithelium, dizziness, dermatitis, allergies etc. They also can cause chronic health complications such as sterility, cancer, bronchitis etc. In this respect, the security of employees in the aspects of working conditions, health and safety are of great importance. Healthy and safe workers gain personal satisfaction aroused from the feeling that they are safe. Such workers show more efficiency and reflect discipline in pesticide usage and thus their relationships with the management and peers improve.

\section{Safety precautions taken in the use of pesticides}

Table 05 shows the workers' view about the safety precautions that the farms have taken in the use of pesticides. It has been identified that safety in the use of pesticides is a prime need of workers in the industry under consideration; the foliage export industry in Sri Lanka. Therefore, studying about present safety conditions provided by the companies and workers' opinion about it is an important aspect. Results of the study depicted in Table 05 show that sixty four percent of the workers are not happy about the safety precautions provided by the companies. This shows that a vast majority of workers are not happy. Further discussions revealed that company's inability to provide appropriate safety conditions and workers inability to stick to whatever conditions provided are contributory to this factor. Workers are of the opinion that the companies have not provided workers with appropriate protective gear. Workers complain that the overalls provided are not suited to tropical conditions and that it is uncomfortable to wear them for more than an hour or so. It is observed that the workers are sent to greenhouses and other enclosed areas that have been sprayed with pesticides. In some organizations, the changing rooms and washing areas are not properly built or maintained. However, the executives of the companies stress that they take every possible precaution. Workers mentioned that proper utensils are not provided to measure and mix pesticides that are used. In some farms hanging pots are used to grow various species of plants and some are hung above the head level. Pesticide mixtures are dribbling from such hanging pots and falling onto bodies and dresses of workers. Some farms have provided low quality gas masks and working gloves that were punctured and damaged. These are some of the reasons for the workers to feel unhappy and sixty four percent of the workers feel that the degree of safety in agrochemical usage in foliage farms is not up to satisfactory standards. The executives had a contrary view: they said 
that every possible precaution was taken in opinion between the two parties. This is unfavourable, hence a barrier to work motivation as a vast majority of workers feel unhappy.

\section{Workers' attitude towards handling pesticides}

Information in Table 06 shows that $80 \%$ of the workers have a negative attitude towards using pesticides by self. They expressed the opinion that agrochemicals do no good to their lives and that they have long lasting negative effects. Twenty four percent of the workers are extremely negative towards handling of pesticides and they oppose every form of handling pesticides within the farm.

Two percent of the workers have a positive attitude towards the use of pesticides. Pesticides and fertilizers are necessary for healthy and vigorous plant growth. Successful plant growth is the secret of sustainability of the export farm, which can ensure continuous employment. This is the reason for two percent of the workers to show a positive attitude towards handling pesticides. Eighteen percent of the workers are not conclusive this regard. This reveals the mismatch of whether they have positive or negative attitudes towards using and handling agrochemicals such as pesticides and fertilizers. It should be noted that this eighteen percent were apportioned among unhappy and happy categories to ease the statistical analysis.

\section{Need for worker safety from pesticides}

Eighty one percent of the workers expressed that they needed safety precautions to safeguard themselves from the pesticides (Table 07). Fifty three percent of the workers strongly expected safety precautions provided by the company while nineteen percent of the workers were not conclusive on their safety. The vast majority shows that workers in foliage farms rank safety from agrochemicals as a higher need. Safety is an important need of humans. This can be translated into security needs as far as work motivation is concerned (Luthans, 1995). Workers who are looking for safety can be motivated for better performance by providing safety from pesticides that they have to use in the farms. The managements should understand this very important and strong need and should consider this when formulating human resource strategies

Table 06: Workers attitude towards handling pesticides by self

\begin{tabular}{lc}
\hline \multicolumn{1}{c}{ Response (Attitude) } & Percentage respondents \\
\hline Extremely negative & 24 \\
Negative & 56 \\
No response & 18 \\
Positive & 2 \\
Extremely positive & None \\
\hline
\end{tabular}

Table 07: Need for worker safety from pesticides

\begin{tabular}{ll}
\hline \multicolumn{1}{c}{ Response on the need for safety } & Percentage of workers (\%) \\
\hline Strongly needed & 53 \\
Moderately needed & 28 \\
No response & 19 \\
\hline
\end{tabular}




\section{Not needed \\ Workers' attitudes towards rewarding for safe working habits}

The rewarding systems should be designed by organizations with the view of motivating their work forces. This is practised in foliage farm sector in various dimensions

According to the study (Table 08) eighty two percent of the workers are happy to be rewarded. Also, they expect their company to recognize safe working habits and the workers who observe safety precautions. Organizations have to identify various safe working habits in order to minimize workers' exposure to pesticides and encourage workers to practice them. Also, companies should be careful in rewarding workers who practice safe working habits best as rewarding best workers itself is a punishment for those who are good but not the best. Also, designing the rewarding system is a matter that has to be resolved in consideration of the corporate financial status.

\section{Encouragement needed by workers}

The findings reveal that seventy nine percent of the workers are looking forward to receive monetary rewards. Expecting monetary rewards is a general trend in the country especially among manual workers who are regarded as the low-income earners. The present economic increment of general price levels etc. are conditions, rate of increment of life index, reasons for this trendThe proportion of workers who wished to have non-monetary rewards for safe working habits was twenty one percent, which is a sizeable component. This study was extended to find out the nature of non-financial rewards that were needed by the workers. The results are
None

given in Table 09. The study revealed that twenty eight percent of the workers out of non-monetary reward seekers, expected early time off with pay. Discussions revealed that most workers are aware that pesticides are hazardous and should not come in contact with the skin. Workers are of the opinion that the workers, who are prone to expose to agrochemicals especially the pesticides, should take a rest or relax in an atmosphere with fresh air. After the spraying, the farm environment is filled with pesticide particles droplets etc. for few hours depending on the wind. If the workers who did the spraying get a time-off, their exposure to agrochemicals would be minimized. Also they can utilize the time for another income generation activity. Seventeen percent of the workers expected formal recognition by way of "safest worker of the year" etc. while sixteen percent were looking for various kinds of gifts. Workers were concerned that the gifts should be contributing to their family income in some way in these stressful national economic situations. The gifts that they expect are dry rations, gift vouchers and schoolbooks for their children etc. It is significant that only two percent of workers wished to be exempted from handling pesticides. This means that ninety eight percent of workers are not hesitant in taking a risk by exposing themselves to occupational hazard of using pesticides but wished to have some return from their organizations. This provides an excellent hierarchy of different types of non-financial rewards that workers are looking for. This hierarchy will be significant for any organization involved in the business of foliage and plant exports, in designing a non-financial rewards system.

Table 08: Workers attitudes towards rewards for Safe working habits

\begin{tabular}{lc}
\hline \multicolumn{1}{c}{ Response } & Percentage Respondents \\
\hline Extremely happy to be rewarded & 53 \\
Happy to be rewarded & 29 \\
No response & 18 \\
\hline
\end{tabular}


Results-orientedness and productivity upon rewards for safe working habits.

It has been an important aspect to study whether rewarding safe working habits results in a higher results-orientedness and a higher productivity.

Labour productivity can be defined as the amount of output per unit time of labour (Adam \& Ebert, 1997). It is observed through the study that seventy nine percent of the workers will contribute to the company with an enhanced productivity if they are rewarded for safe working habits (Table 10). Workers will appreciate such rewards and be motivated to produce a higher output thereby enhancing the labour productivity. Further, they will be more results conscious and work more hard. Only three percent of the workers will not be showing a higher output while eighteen percent did not show any response. Of the seventy nine percent of workers, forty one percent rank work safety as a high priority and will greatly enhance their productivity when the company provides rewards for safe working habits.

Table 9: Types of non-financial rewards expected by workers

\begin{tabular}{lc}
\hline \multicolumn{1}{c}{ Type of non-financial reward expected } & Percentage requested \\
\hline 1. Early time-off with pay. & 28 \\
2. Formal recognition such as "safest worker of the & 17 \\
month" etc. & 16 \\
3. Gifts. & 10 \\
4. Loan facilities. & 9 \\
5. Company paid holidays. & 7 \\
6. Quick permanency. & 4 \\
7. Reimbursement of medical bills and free medical & 3 \\
check-ups. & 3 \\
8. Further training on safety. & 2 \\
9. Jobs with more responsibility. & 1 \\
10. Keep out from spraying pesticides. & \\
11. Verbal recognition and encouragement. & \\
\hline
\end{tabular}

Table 10: Labour productivity upon rewarding for safe working habits

\begin{tabular}{lc}
\hline Response on productivity upon rewarding & Percentage of respondents \\
\hline 1. Productivity will be strongly enhanced. & 41 \\
2. Productivity will be enhanced. & 38 \\
3. No response. & 18 \\
4. Productivity will not be significantly enhanced. & 3 \\
\hline
\end{tabular}

Table 11: Workers opinion on company's encouragement of safe working habits.

\begin{tabular}{lc}
\hline \multicolumn{1}{c}{ Opinion on encouragement of safe working habits } & Percentage respondents \\
\hline 1. Company strongly encourages. & None \\
2. Company moderately encourages. & 11 \\
3. Company is neutral. & 86 \\
4. Company ignores encouragement. & 3 \\
\hline
\end{tabular}


Workers are vigilant about what their employers do to make them satisfied. Many successful organizations try to keep their employees; especially the manual grades, satisfied. This is an important aspect of work motivation. Also, it is important for a company to let its workers know that the company cares for them. Workers' opinion that their company encourages them to perform safely is a factor positively contributing towards work motivation.

\section{Organizational encouragement for workers with safe working habits}

According to the results (Table 11) of the study, it is alarming that only eleven percent of the workers know and expressed that the companies encourage them on safe working practices; eighty six percent feel that the companies show a neutral stance on encouraging safe working habits and three percent feel that their companies ignore these even if the safe working habits are well displayed by contact with pesticides. There is a competition among workers in the farms to work in the packing area/shed. Virtually all the other manual grades have direct contact with pesticides that are used by the farms.

Workers are aware about how they come into contact with pesticides. They are demotivated when they are assigned for spraying. Rewards and other strategies should be used to motivate them for spraying. Proper protective gear should be provided. Explaining the workers that they are fully protected could motivate workers. Therefore, it is evident in this study that companies do not use this subtle strategy of making the employees know that their companies care for them. Also, safe working habits are beneficial for the company. It was found that safe working reduces absenteeism (Luthans, 1995). Therefore, companies should encourage safe working habits.

\section{Mode of contact with pesticides}

Ninety one percent of workers came into contact when using or dispensing the pesticides or while cleaning of dispensing equipment and containers (Table 12) while six percent is accounted for contact during storage of pesticides and disposal of expired material. It is interesting to reveal that three percent of farm workers do not come into direct contact with pesticides. The packing room workers are the main category that does not come into direct

them for spraying and other related activities that demand handling of pesticides. However, the following were noticed very commonly: mixing of pesticides with bare hands, leaking spray equipment, working schedules with wrong technique of spraying and mixing of pesticide cocktails with two or more formulations. Also, some farms store pesticides in unsealed or leaking containers. These should be avoided as much as possible. Also, use of methods that do not require dispensing equipment, should be avoided.

Table 12. Common modes of direct contact with pesticides

\begin{tabular}{lc}
\hline \multicolumn{1}{c}{ Mode of contact of agrochemicals } & Percentage of workers \\
\hline 1. Dispensing / cleaning of equipment and & 91 \\
containers. & \\
2. Storage of pesticides and disposal of expired & 6 \\
material. & None \\
3. Transport of pesticides. & 3 \\
4. Farm workers who do not come into contact. & \\
\hline
\end{tabular}




\section{CONCLUSIONS}

Foliage plant exports industry has been identified as an important industry in Sri Lanka. A large number of employments are created through this industry. Extensive usage of pesticides that are hazardous to humans is a common feature of the commercial foliage sector in Sri Lanka. Workers in commercial farms are in a psychologically conflicting state as they are trapped between the use of pesticides and their own safety. Therefore, this affects work motivation.

This study undertaken to analyse the working environment and safe working habits of handling pesticides by workers provided an insight into how that affect workers' attitudes, response and satisfaction which in turn have an effect on work motivation. This study yields the result that workers' satisfaction, happiness and positive attitudes are dependent upon the present working conditions in the farms, safety precautions taken in the use of pesticides and the workers' attitudes towards handling pesticides by themselves; the three variables of the study. Since work motivation is linked with satisfaction, positive attitude and happiness, it is concluded that the above three variables have an influence on work motivation. This study revealed that the workers have negative attitudes towards using pesticides even though they have to use them in the working situations and are unhappy about the safety precautions provided at present. Also, the workers are not happy about the overall working conditions regarding use of pesticides. Therefore, this is a deterrent to worker motivation. Workers need more safety precautions when using pesticides. Workers are not hesitant of taking the risk of using the pesticides provided they are rewarded; monetary rewards in particular. Also, it was revealed that they will perform their tasks with enhanced productivity, if rewarded for safe working habits.

\section{Recommendations to improve work motivation}

\section{a. Strategies based on reinforcement of safe working habits}

Safe working habits must be reinforced in order for workers to be encouraged, thereby achieving a higher work motivation. The researcher suggests the following ways of reinforcements;

1. Make a fair criterion to adjudge "the safest worker of the week/month/year etc" and recognize him/her. By doing this, amidst all the hazards of the use of pesticides in the workplace, the workers will be more safe-conscious and motivated better towards their work.

2. Safe working habits are rewarded financially as seventy nine percent of workers need so. Better salary increments on recognition, safest worker's contribution to Employees Provident Fund also are paid by the organization for the coming year and cash rewards are some of the financial rewards that can be offered.

3. Offering of material rewards such as; gifts, provision of dry rations for a particular period; etc. are also practical solutions

4. Offering of other non-financial rewards such as; early time off with pay, loan facilities to purchase household items etc., company paid holidays, quick permanency for casual and contract workers who are more safe conscious etc. will also have a positive effect on worker motivation.

Offering of company shares to the safest worker, paper advertisements to recognize the safest worker are some of the other special rewards a company could offer to its workers who are safety conscious.

\section{b. Strategies based on other aspects that have been revealed during discussions}

1. Workers will have to be made understood that they don't have to worry as the organization is taking all the precautions relevant to safety. And, if they follow all these, the 
workers who dispense the pesticides will be completely safe or safe to a very great extent.

2. Workers will have to be made understood that there shouldn't be a big need for safety as company is taking all the possible precautions on behalf of the workers. It is revealed that the companies in which this study was done have not understood the importance of implanting above facts in the minds of workers in order to have a better work motivation.

3. Contact a reputed company that sells pesticides and request to have demonstrations as to how these chemicals can be used safely and types of equipment that have to be used, if such services are available. Workers will be encouraged to compare how they do it and how it should actually be done. This will improve morale of workers and a sense of confidence can be built in the minds of workers.

4. Teach them the safe working habits by displaying posters etc. These can be obtained from the Sri Lanka Crop Protection Association

5. Closely monitor the workers and identify accident-prone workers, despite all the precautions provided. Providing a training programme for the workers would be a helpful strategy. Discontinuation of service may be an end result if these workers continue to be careless despite training.

6. When recruiting workers, accidentprone candidates should be identified and recruiting them should be avoided.

7. Early recognition and proper management of pesticide poisoning is extremely important. Regular medical check-ups handled by a qualified medical professional are suitable. It is suggested that the companies should get the assistance from the Deputy Commissioner of Labour (Industrial Health) of the Labour Secretariat for the above matter. It was revealed at the discussions that most of the companies do not even seem to know that there's such an official available in Sri Lanka. Development of a proper and a quick reporting system on cases of pesticide poisoning in organizations is another strategy. Farms or farm authorities should not be penalized but necessary action should be taken to reduce the hazard.

8. Have medical check-ups for workers who return from extended sick leave and workers who have been absent (excused or not) for extended periods. This will show that the company cares for workers.

9. Workers should be made aware that they are covered by Workmen's' Compensation Insurance and that the company pays the premium for them.

10. In addition, it is suggested that the organizations pay attention to direct measurements such as;

- Frequency Rate (FR) of accidents and illness due to handling of pesticides. This measures the number of times that the workers meet accidents.

- Severity Rate (SR) of accidents and illness due to handling of pesticides. This measures the length of time lost due to accidents and illness resulted by pesticides.

- Charting of above parameters against time and paying an attention on trends will be an interesting and a useful exercise.

11. Also, workers and executives were interested about non-chemical pest control methods. Naito (2002) recommended that use of rice husk ash, use of trap crops and use of better agronomic practices are excellent measures. Other non-chemical pest control measures are the cultural and physical control tools which include regulation of temperature, weed control around greenhouses, use of pheromone traps and proper crop hygiene (Yano, 2002).

12. Integrated Pest and Disease Management (IPDM) is a popular approach in a number of countries. This includes judicious use of pesticides. IPDM is not popularly practised in commercial farms in Sri 
Lanka. The farms are using polytunnels, but are not fully protected cultivations, hence difficult to practise IPDM. Also, it is a long and a laborious process to obtain permit to identify, import and develop natural enemies and other biological controlling agents. However, IPDM is a good alternative as this can reduce the usage of chemical pesticides while achieving a better control.

13. Asian countries such as China, Taiwan and India are world leaders in the production of bio-pesticides and raising beneficial insects. (Schillhorn van Veen, 2003). Sri Lanka is far behind in this respect. Plant extracts such as Neem, biological control agents, safer formulations and target specificity are some of the strategies that can be used in commercial farms.

14. The study revealed that investment in quality sprayers, quality protective gear and price of pesticides are extremely high and are significant onfarm costs. To accommodate these, some farms attempt to use poor quality equipment (with poor technical result, higher than needed product concentrations and high risk to workers) or use methods that do not require equipment. There is a need to establish an independent or government unit or a body for periodic auditing of these aspects. They should do farm visits with a view of improving the situations but not to penalize commercial farms.
15. It was evident in the study that some executives, supervisors and workers are poorly informed and insufficiently understand human health risk, risk of development of pesticide resistance, to what extent the protective measures protect them, which parts of the body can absorb pesticides, safe use of pesticides etc. Same managers still believe the "Kill-all" type of pesticides and hundred percent control of pests. Some farms employ female workers for spraying. Therefore, properly designed training programmes seem to be mandatory.

As organizations operate in complex environments, their managements will have to respond to a wide variety of variables to gain a competitive edge. However, it has to be stressed that managers will have to have a successful dialogue and link with it's workers so that they can understand the needs and wants of workers and respond to them. In this context, it has to be understood that an integrated approach incorporating as many as above proposals will have to be taken by the organizations in order to have a better work motivation.

With above suggestions, the researcher expects that the organizations show the workers that they are looked-after by the organizations. An improved work motivation through positive attitudes, happiness and satisfaction will be the ultimate expectation.

\section{REFERENCES}

Adam, Ebert, E. and Ebert, R. J., (1997). Production and operation Management, $5^{\text {th }}$ E, Prentice - Hall of India Ltd, New Delhi, India, pp $46-49$.

Luthans, Fred., (1995). Organizational Behaviour $7^{\text {th }}$ Edition, McGraw - Hill Inc., pp 150 151.

Naito, Atsushi, (2002), Attempts to develop low cost technology to manage Soya Bean insects in Indonesia, Symposium on Production and Utilization of Pesticides, Asian Productivity Organization, Tokyo, Japan, pp.17.

Schillhorn Van Veen, Tjaart W., (2002). Agricultural Pest Management at A crossroad: Old Tools, New Perspective, Risks and Opportunities, Production and Utilization of Pesticides in Asia and the Pacific., Asian Productivity organization, Tokyo, Japan, pp, $131-151$.

Sri Lanka customs, (2000) External Trade statistics, The Government Press, Colombo, Sri Lanka.

Yano, Eiji, (2002), Recent progress in IPM of vegetables, Symposium on Production and 
Utilization of Pesticides, Asian Productivity Organization, Tokyo, Japan, pp. 18. 